\title{
Periprocedural Use of Oral Anticoagulation Therapy in Patients Undergoing Atrial Fibrillation Ablation
}

\author{
ILIR MARAJ, MD, ${ }^{1}$ MARIO D. GONZALEZ, MD, ${ }^{1}$ and GERALD V. NACCARELLI, MD ${ }^{1}$ \\ ${ }^{1}$ Cardiology Division/EP Section, Department of Medicine, Heart and Vascular Institute, Penn State Health Milton \\ S. Hershey Medical Center, Penn State College of Medicine, Hershey, PA, USA
}

\begin{abstract}
Atrial fibrillation (AF) is the most common sustained arrhythmia encountered in clinical practice today. For those who present with it, one of the most major risks associated with the condition is stroke. AF is associated with a fivefold increased risk of stroke and thromboembolism. Oral anticoagulation has been the cornerstone of stroke prevention in patients with AF. In some individuals who exhibit a higher risk of bleeding, other alternatives for stroke prevention have been sought, including the use of left atrial appendage occlusion devices and surgical exclusion of the left atrial appendage. Catheter ablation is an important treatment strategy in those patients for whom a rhythm control strategy has been selected. This article reviews some of the available anticoagulant drug options and their use prior to, during, and after catheter ablation.
\end{abstract}

KEYWORDS. Atrial fibrillation, catheter ablation, NOAC.
ISSN 2156-3977 (print) ISSN 2156-3993 (online) CC BY 4.0 license

C 2018 Innovations in Cardiac Rhythm Management

\section{Introduction}

Atrial fibrillation (AF) is the most common sustained arrhythmia encountered in clinical practice. According to current data, more than 33 million people worldwide carry the diagnosis of $\mathrm{AF}^{1}{ }^{1}$ In the United States, it is estimated that three to five million people have $\mathrm{AF}$, with the number projected to exceed eight million by $2050 .^{2} \mathrm{AF}$ causes many symptoms and contributes to 450,000 hospitalizations and more than 99,000 deaths annually in the US. ${ }^{3,4}$ One of the major risks associated with AF is stroke. $\mathrm{AF}$ is associated with a fivefold increased risk of stroke and thromboembolism. ${ }^{5}$ Stroke prevention is therefore

Dr. Gonzalez reports presenting lectures on behalf of Janssen Pharmaceutica. Dr. Naccarelli reports that he is a consultant and has received research support from Janssen Pharmaceutica. Dr. Maraj reports no conflicts of interest for the published content.

Manuscript received November 28, 2017. Final version accepted December 30, 2017.

Address correspondence to: Ilir Maraj, MD, Heart and Vascular Institute, Penn State Health Milton S. Hershey Medical Center, Penn State College of Medicine, Room H1344G, 500 University Drive, Hershey, PA 17033, USA. Email: imaraj@pennstatehealth.psu.edu. essential in patients with AF. Oral anticoagulation has been the cornerstone of stroke prevention in patients with $\mathrm{AF}$, especially in those with a higher risk of stroke. In view of the limitations in patients with higher bleeding risks, other alternatives have been sought for stroke prevention, including the use of left atrial appendage occlusion devices and surgical exclusion of the left atrial appendage. Catheter ablation is an important treatment strategy in cases where a rhythm control strategy has been chosen. In fact, it is the recommended approach in patients with symptomatic paroxysmal and persistent $\mathrm{AF}$ with at least one failed antiarrhythmic medication attempt. ${ }^{6}$ Catheter ablation is associated with risks including stroke and transient ischemic attack; therefore, the payment of close attention to anticoagulation before, during, and after the procedure is very important so as to minimize any risks. ${ }^{7}$

\section{Preprocedural systemic anticoagulation options for stroke prevention}

Adequate periprocedural anticoagulation is essential to reduce the risk of stroke, minimize bleeding complications 
from the ablation procedure, and achieve quality outcomes. Current guidelines recommend administration of an anticoagulant for at least three weeks prior to radiofrequency ablation. Vitamin $\mathrm{K}$ antagonists (VKAs) have been the primary anticoagulation medications for patients with a higher risk of stroke $\left(\mathrm{CHA}_{2} \mathrm{DS}_{2}\right.$-VASc score $\geq 2$ ). With the advent of newer anticoagulation medications, however, the scope of therapy has significantly broadened and these agents have emerged as a viable therapy option in stroke prevention. ${ }^{8}$

\section{Vitamin $K$ antagonists}

Warfarin has been used as an anticoagulant for decades and is the most frequently prescribed medication worldwide. ${ }^{9}$ Warfarin has an inhibitory effect on multiple coagulation factors (II, VII, IX, and X); however, it also has a very narrow therapeutic index and interacts with a variety of foods and medications. In addition, patients need to routinely monitor international normalized ratio (INR) levels and make dose adjustments accordingly. ${ }^{10}$ In the early stages of AF ablation as a procedure, it was standard practice to stop warfarin before the procedure and "bridge" with either enoxaparin or heparin (Table 1). However, this strategy was associated with a high rate of access site bleeding complications. ${ }^{11}$ As a result, multiple studies were performed and now suggest that it is safe to perform $\mathrm{AF}$ ablation without interrupting warfarin (Table 1). In a large, multicenter, nonrandomized study in 2010, Di Biase et al. showed that uninterrupted use of warfarin with an INR target $>2$ in combination with using an open-irrigated ablation catheter can reduce the risk of periprocedural stroke without increasing the risk of hemorrhagic complications as compared with interrupted warfarin bridged with enoxaparin..$^{8,12}$ The Role of Coumadin in Preventing Thromboembolism in AF Patients Undergoing Catheter Ablation (COMPARE) trial showed that uninterrupted anticoagulation with warfarin was superior in comparison with interrupted warfarin-based strategies employing bridging. ${ }^{13}$ There were more strokes reported in the warfarin-interrupted group as compared with in the warfarin-continued group (INR goal: 2-3.5). Warfarin discontinuation emerged as a strong predictor of periprocedural thromboembolism [odds ratio (OR): 13, 95\% confidence interval (CI): 3.1-55.6; $\mathrm{p}<0.001$ ].

\section{Novel oral anticoagulants}

Novel oral anticoagulants (NOACs) are relatively new medications approved by the US Food and Drug Administration (FDA) for stroke prevention in patients with nonvalvular AF. The main NOACs approved thus far include dabigatran as a direct thrombin inhibitor and apixaban, rivaroxaban, and edoxaban as factor Xa inhibitors. Evidence and several meta-analyses have demonstrated NOACs to have a similar efficacy and safety to that of warfarin in the setting of catheter ablation. ${ }^{4}$ In addition, when compared with warfarin, NOACs offer more predictable pharmacokinetics, shorter half-lives, and more convenient periprocedural management.

Dabigatran. Dabigatran is a direct thrombin inhibitor with selective and reversible binding to thrombin. ${ }^{15}$ The prodrug, dabigatran etexilate, is absorbed and converted to the active metabolite dabigatran. ${ }^{16}$ Almost all of the absorbed prodrug is converted to dabigatran and most of the drug is excreted unchanged in the urine. Peak plasma concentration is reached at approximately two hours after oral administration. ${ }^{16}$ The half-life of dabigatran is 12 hours to 14 hours in elderly healthy subjects. ${ }^{17}$ Dabigatran is contraindicated in instances of severe renal disease. It was approved by the FDA in 2010 for stroke prevention in patients with $\mathrm{AF}$ following the release of the results of the Randomized Evaluation of Long-Term Anticoagulation Therapy (RE-LY) trial. ${ }^{18}$ This was a

Table 1: Strategies to Manage Anticoagulation Before, During, and After Ablation

\begin{tabular}{|c|c|c|c|}
\hline Strategy & Before Ablation & During Ablation & After Ablation \\
\hline $\begin{array}{l}\text { Interrupted } \\
\text { warfarin }\end{array}$ & $\begin{array}{l}\text { - Five days before } \\
\text { the procedure, stop } \\
\text { warfarin and bridge } \\
\text { with LMWH }\end{array}$ & $\begin{array}{l}\text { - Administer } \\
\text { heparin } \\
\text { - Achieve an ACT } \\
>300 \text { seconds }\end{array}$ & $\begin{array}{l}\text { - Stop heparin } \\
\text { - Consider protamine } \\
\text { - Remove sheath when ACT is less than } 200-250 \text { seconds }^{7} \\
\text { - Restart warfarin and bridge with LMWH until INR is in } \\
\text { therapeutic range }\end{array}$ \\
\hline Interrupted NOAC & $\begin{array}{l}\text { - Five days before the } \\
\text { procedure, stop NOAC } \\
\text { and switch to warfarin } \\
\text { or bridge with LMWH }\end{array}$ & $\begin{array}{l}\text { - Administer } \\
\text { heparin } \\
\text { - Achieve an ACT } \\
>300 \text { seconds }\end{array}$ & $\begin{array}{l}\text { - Stop heparin } \\
\text { - Consider protamine } \\
\text { - Remove sheaths when ACT is less than } 200-250 \text { seconds }^{7} \\
\text { - Resume NOAC three to five hours after sheath removal }\end{array}$ \\
\hline $\begin{array}{l}\text { Uninterrupted } \\
\text { warfarin }\end{array}$ & - Continue warfarin & $\begin{array}{l}\text { - Administer } \\
\text { heparin } \\
\text { - Achieve an ACT } \\
>300 \text { seconds }\end{array}$ & $\begin{array}{l}\text { - Stop heparin } \\
\text { - Consider protamine } \\
\text { - Remove sheath when ACT is less than } 200-250 \text { seconds }^{7} \\
\text { - Continue warfarin }\end{array}$ \\
\hline $\begin{array}{l}\text { Uninterrupted } \\
\text { or minimally } \\
\text { interrupted NOAC }\end{array}$ & $\begin{array}{l}\text { - Stop NOAC 12-24 hours } \\
\text { before the procedure or } \\
\text { continue uninterrupted }\end{array}$ & $\begin{array}{l}\text { - Administer } \\
\text { heparin } \\
\text { - Achieve an ACT } \\
>300 \text { seconds }\end{array}$ & $\begin{array}{l}\text { - Stop heparin } \\
\text { - Consider protamine } \\
\text { - Remove sheath when ACT is less than } 200-250 \text { seconds }^{7} \\
\text { - Resume NOAC use three to five hours after sheath removal }\end{array}$ \\
\hline
\end{tabular}

LMWH: low-molecular-weight heparin; ACT: activated clotting time; INR: international normalized ratio; NOAC: novel oral anticoagulant. 
randomized clinical trial that compared two fixed-dose regimens of dabigatran (110 mg twice daily and $150 \mathrm{mg}$ twice daily) with dose-adjusted warfarin in patients with $\mathrm{AF}$ and a high risk of stroke. Both dabigatran doses were noninferior to warfarin with respect to stroke prevention. In addition, the 150-mg dose of dabigatran was superior to warfarin with regard to stroke or systemic embolism prevention and the 110-mg dose was superior to warfarin with regard to major bleeding prevention.

Multiple small studies have suggested that minimally interrupted dabigatran therapy is safe and effective. In a study by Kim et al., it was demonstrated that, when dabigatran was withheld for approximately 24 hours before the radiofrequency ablation of $\mathrm{AF}$ and resumed four hours after vascular hemostasis, it appeared to be as safe and as effective as the use of uninterrupted warfarin for periprocedural anticoagulation. ${ }^{19}$ However, in a large, multicenter, prospective study, Lakkireddy et al. showed that periprocedural dabigatran use significantly increased the risk of bleeding or thromboembolic complications when compared with uninterrupted warfarin therapy in patients undergoing AF ablation. ${ }^{20}$ In this study, patients taking dabigatran $150 \mathrm{mg}$ orally twice daily prior to ablation were compared with matched patients taking uninterrupted warfarin (therapeutic INR). Dabigatran was withheld about 12 hours prior to ablation.

The Uninterrupted Dabigatran Etexilate in Comparison to Uninterrupted Warfarin in Pulmonary Vein Ablation (RE-CIRCUIT) study was the only randomized study that was a head-to-head comparison of uninterrupted dabigatran (150 mg orally twice daily) versus uninterrupted warfarin (INR: 2-3) for AF abltion. ${ }^{21}$ This was a multicenter study wherein 704 patients were randomized to two groups. The major bleeding incidence in patients in the dabigatran group was significantly lower than that in the warfarin group [five patients $(1.6 \%)$ versus 22 patients $(6.9 \%)$; absolute risk difference: $25.3 \%$; relative risk reduction (RR): $77 \%$ ]. There were six patients who developed cardiac tamponade in the warfarin group versus only one in the dabigatran group. No strokes or thromboembolic events occurred in the dabigatran arm, while one transient ischemic attack occurred in the warfarin arm.

Rivaroxaban. Rivaroxaban is an oral, direct, specific factor Xa inhibitor. ${ }^{22}$ It is absorbed rapidly, with maximum plasma concentrations being reached at two hours to four hours after tablet intake. Its oral bioavailability is high $(80 \%-100 \%)$ when taken with food and elimination from plasma occurs with a terminal half-life of five hours to nine hours. ${ }^{23}$ The elimination of rivaroxaban occurs via renal elimination of unchanged drug and via metabolic degradation of the drug. Approximately one-third is eliminated in the urine as unchanged active drug. ${ }^{24}$ Multiple studies have shown that rivaroxaban is safe to use in patients with nonvalvular AF undergoing catheter ablation.

Rivaroxaban was approved by the FDA in 2012 for stroke prevention in nonvalvular AF following the results of the Rivaroxaban Once Daily Oral Direct Factor Xa Inhibition
Compared with Vitamin K Antagonism for Prevention of Stroke and Embolism Trial in AF (ROCKET AF) study. ${ }^{25}$ The ROCKET-AF trial was a randomized, multicenter trial. In this study, 14,264 patients with nonvalvular AF and at least a moderate risk of stroke (mean $\mathrm{CHADS}_{2}$ score, 3.5) were randomized to receive either rivaroxaban (20 mg daily or $15 \mathrm{mg}$ daily if glomerular filtration rate was 30-49 $\mathrm{mL} / \mathrm{min}$ ) or dose-adjusted warfarin (INR: 2-3). At a mean follow-up time of two years, rivaroxaban was found to be noninferior to warfarin for the composite endpoint of stroke or systemic embolism, without increasing the bleeding risk. There were similar rates of thromboembolism $(1.1 \%$ in the rivaroxaban arm versus $2.1 \%$ in the warfarin arm; $\mathrm{p}=0.41)$ and major bleeding $(1.6 \%$ in the rivaroxaban arm versus $4.2 \%$ in the warfarin arm; $\mathrm{p}=0.112$ ).

The Study Exploring Two Treatment Strategies in Patients with AF Who Undergo Catheter Ablation Therapy (VENTURE-AF) trial was the first prospective, randomized trial of uninterrupted rivaroxaban and VKAs in patients with nonvalvular AF undergoing catheter ablation. ${ }^{26}$ In this trial, 248 nonvalvular AF patients were assigned to uninterrupted rivaroxaban ( $20 \mathrm{mg}$ once daily) or to an uninterrupted VKA prior to undergoing catheter ablation and for four weeks afterwards. The primary endpoint was a major bleeding event after catheter ablation. Secondary endpoints included thromboembolic events (composite of stroke, systemic embolism, myocardial infarction, and vascular death) and other bleeding or procedure-attributable events. Notably, it was found that the incidence of major bleeding was low $(0.4 \%$; one major bleeding event). Similarly, thromboembolic events were also low $(0.8 \%$; one ischemic stroke and one vascular death occurred). All events occurred in the VKA arm and after ablation. This trial demonstrated that the use of uninterrupted rivaroxaban for catheter ablation of AF is feasible and that event rates were similar to those of warfarin.

Apixaban. Apixaban is another NOAC recently approved by the FDA in 2012 for stroke prevention in nonvalvular AF patients. It is a direct factor Xa inhibitor that demonstrates rapid absorption and a half-life of 12 hours and is $25 \%$ renally excreted.$^{27}$ The results of the Apixaban for Reduction in Stroke and Other Thromboembolic Events in Atrial Fibrillation (ARISTOTLE) trial led to apixaban approval. ${ }^{28}$ In this trial, 18,201 patients with nonvalvular $\mathrm{AF}$ and one or more stroke risk factors were randomized to receive either apixaban or warfarin. Specifically, patients were randomized to receive either apixaban $5 \mathrm{mg}$ twice daily ( $2.5 \mathrm{mg}$ twice daily in patient $\geq 80$ years, body weight $\leq 60 \mathrm{~kg}$, and serum creatinine $\geq 1.5 \mathrm{mg} / \mathrm{dL}$ ) or dose-adjusted warfarin (INR range: $2-3$ ). With a median follow-up of 1.8 years, apixaban was found to be superior with regard to rate of stroke or systemic embolism (annual incidence: $1.27 \%$ versus $1.6 \%$ ). In addition, apixaban was associated with less major bleeding (2.13\% per year versus 3.09\% per year). The rate of intracranial hemorrhage was $0.33 \%$ per year in the apixaban group and $0.80 \%$ per year in the warfarin group (hazard ratio: 0.42 , 95\% CI: $0.30-0.58 ; \mathrm{p}<0.001)$. 
In a prospective, multicenter registry of AF patients undergoing radiofrequency catheter ablation, Di Biase et al. demonstrated that uninterrupted apixaban administration was feasible and effective in preventing clinical and silent thromboembolic events without increasing the risk of major bleeding. ${ }^{29}$ In this study, there were no statistical differences regarding major complications ( $1 \%$ versus $0.5 \% ; \mathrm{p}=1)$, minor complications $(3.5 \%$ versus $2.5 \%$; $\mathrm{p}=$ $0.56)$, or total bleeding complications (4.5\% versus $3 \%$; $p$ $=0.43$ ) between the apixaban and warfarin groups. There were also no symptomatic thromboembolic complications.

The Apixaban Evaluation of Interrupted or Uninterrupted Anticoagulation of AF (AEIOU) trial-a prospective, multicenter clinical study (NCT02608099)—showed that both uninterrupted and minimally interrupted apixaban (one dose withheld) at the time of AF ablation were associated with a very low rate of thromboembolic events and that rates of both major $(<2 \%)$ and clinically significant bleeding were similar to those seen with uninterrupted warfarin. ${ }^{30}$

The Apixaban During AF Catheter Ablation: Comparison to Vitamin K Antagonist Therapy (AXAFA) trial (NCT02227550) is another major randomized clinical trial currently underway using uninterrupted apixaban as compared with uninterrupted VKA therapy.

Edoxaban. Edoxaban is an oral direct factor Xa inhibitor with $62 \%$ oral bioavailability that achieves maximum concentration in one to two hours and is $50 \%$ renally excreted. $^{31,32}$ Edoxaban was approved by the FDA in 2015. The major trial that led to edoxaban's approval was the Effective Anticoagulation with Factor Xa Next Generation in AF-Thrombolysis in Myocardial Infarction 48 (ENGAGE AF-TIMI 48) study. ${ }^{33}$ In this trial, 21,105 patients with moderate- to high-risk AF were randomized to receive dose-adjusted warfarin (INR: 2-3), high-dose edoxaban (60 mg once daily), or low-dose edoxaban (30 $\mathrm{mg}$ once daily). With a median follow-up of 2.8 years, both regimens of edoxaban were found to be noninferior to warfarin with respect to the primary efficacy endpoint of stroke or systemic embolism (in the warfarin group, a stroke or systemic embolic event occurred at a rate of $1.5 \%$ per year versus $1.18 \%$ in patients in the high-dose edoxaban group and $1.61 \%$ in the low-dose edoxaban group). The rate of ischemic stroke was similar between high-dose edoxaban and warfarin but was higher with the low-dose edoxaban regimen. The incidence of hemorrhagic stroke and the rate of death from cardiovascular causes were significantly lower with both edoxaban regimens than with warfarin. Edoxaban was also associated with consistently lower dose-related rates of all types of bleeding, including major bleeding, intracranial bleeding, and life-threatening bleeding. The single exception was gastrointestinal bleeding, which occurred more frequently with high-dose edoxaban but less frequently with low-dose edoxaban than it did with warfarin. One interesting finding in this trial was the reduced efficacy of edoxaban in a patient with a glomerular filtration rate
$>95 \mathrm{~mL} / \mathrm{min} \cdot{ }^{33}$ In a recent study evaluating patients in the ENGAGE AF-TIMI 48 trial undergoing AF ablation, treatment with edoxaban was associated with a low risk of ischemic and bleeding events during the first 30 days after ablation. ${ }^{34}$

Overall, NOACs compare favorably to warfarin in the prevention of stroke in patients with nonvalvular AF. A recent large meta-analysis that included 71,683 patients from four major trials comparing NOACs versus warfarin for stroke prevention (ie, RE-LY, ARISTOTLE, ROCKET $\mathrm{AF}$, and ENGAGE AF-TIMI 48$)^{35}$ showed that NOACs had a favorable risk-benefit profile, with significant reductions in stroke, intracranial hemorrhage, and mortality and with similar major bleeding rates as warfarin but increased gastrointestinal bleeding. NOACs reduced stroke or systemic embolic events by $19 \%$ as compared with warfarin (RR: 0.81, 95\% CI: 0.73-0.91; $p<0.0001$ ), mainly driven by a reduction in hemorrhagic stroke (RR: 0.49, 95\% CI: 0.38-0.64; p < 0.0001). NOAC use also significantly reduced all-cause mortality (RR: 0.90, 95\% CI: $0.85-0.95 ; \mathrm{p}=0.0003$ ) and intracranial hemorrhage (RR: 0.48 , 95\% CI: $0.39-0.59$; $\mathrm{p}<0.0001)$ but increased gastrointestinal bleeding (RR: 1.25; 95\% CI: $1.01-1.55 ; \mathrm{p}=0.04$ ).

\section{Intraprocedural anticoagulation}

Systemic anticoagulation with unfractionated heparin during $\mathrm{AF}$ ablation is very important. It is recommended that heparin be administered prior to or immediately following transseptal puncture and adjusted to maintain a target activated clotting time (ACT) of 300 seconds or more. ${ }^{7}$ It has been shown that early anticoagulation with heparin significantly decreases the risk of clot formation. ${ }^{36,37}$

In a recent large meta-analysis of 7,150 patients, Briceno et al. demonstrated that performing AF catheter ablation with a target ACT of $>300$ seconds decreased the risk of thromboembolic events without increasing bleeding risk. ${ }^{38}$ Patients with ACTs of $>300$ seconds had fewer thromboembolic events (OR: 0.51, 95\% CI: 0.35-0.74) and less bleeding (OR: 0.70, 95\% CI: 0.60-0.83) than did patients with ACTs of $<300$ seconds when using any type of oral anticoagulation. Another interesting finding in this study was that the use of VKAs was associated with reduced heparin requirements and less time needed to achieve a target ACT as compared with NOAC use.

Most operators administer heparin just prior to transseptal puncture. According to the 2017 Heart Rhythm Society/European Heart Rhythm Association/European Cardiac Arrhythmia Society/Asia Pacific Heart Rhythm Society/Sociedad Latinoamericana de Estimulacion Cardiaca y Electrofisiologia expert consensus statement on catheter and surgical ablation of $\mathrm{AF}$, the heparin loading dose should be administered followed by heparin infusion. The ACT level should be checked initially every 10 minutes to 15 minutes until therapeutic levels are achieved and then every 15 minutes to $30 \mathrm{~min}-$ utes thereafter. The initial heparin loading dose should 
be 50 units $/ \mathrm{kg}$ in patients anticoagulated with warfarin, 75 units $/ \mathrm{kg}$ in patients not on anticoagulation, and 120 units/ kg in patients on NOACs. The heparin dose should be adjusted to maintain an ACT of 300 seconds to 350 seconds throughout the procedure. ${ }^{7}$ Transseptal sheaths should be infused continuously with heparinized saline to reduce the risk of thrombus formation. ${ }^{36}$

\section{Anticoagulation following atrial fibrillation ablation}

Due to postablation hypercoagulability, it is a consensus that anticoagulation should be continued for at least two months after ablation, irrespective of stroke risk or rhythm status. ${ }^{7}$ Immediately postprocedure, if a patient was on a NOAC, most operators would restart the medication three hours to five hours after sheath removal. If a patient was on warfarin and the procedure was performed on therapeutic INR (uninterrupted strategy), a warfarin dose can be given at the usual time of night. If considering a patient undergoing AF ablation who is utilizing the interrupted coagulation strategy, then lowmolecular-weight heparin, enoxaparin $0.5 \mathrm{mg} / \mathrm{kg}$ to $1 \mathrm{mg} / \mathrm{kg}$ twice daily, or heparin can be given until the INR becomes therapeutic. ${ }^{7,39}$ In patients with a high stroke risk profile $\left(\mathrm{CHA}_{2} \mathrm{DS}_{2}\right.$-VASc score $\left.\geq 2\right)$, current guidelines recommend long-term anticoagulation after AF catheter ablation.

\section{Anticoagulation reversal agents}

To reduce the severity of bleeding complications from anticoagulation, reversal agents are frequently required. The most common reversal agents to treat warfarin toxicity are vitamin $\mathrm{K}$ and fresh frozen plasma (FFP). The lack of antidotes and reversal agents for NOACs (with the exception of dabigatran) quite often limits the use of these medications.

\section{Warfarin antagonists}

Vitamin $\mathrm{K}$ is the essential cofactor for the synthesis of vitamin $\mathrm{K}$-dependent proteins and serves as the first-line treatment for patients with warfarin-associated coagulopathy. ${ }^{40}$ FFP contains coagulation factors-including factors II, VII, IX, and X in concentrated form-and is used for combating severe bleeding due to warfarin toxicity. ${ }^{40,41}$

Four-factor prothrombin complex concentrate (4F-PCC) (Table 2) contains factors II, VII, IX, and X prepared from plasma and was approved by the FDA in 2013 for use in cases of severe bleeding due to VKA therapy. 4F-PCC products are lyophilized items that are administered in smaller volumes over shorter periods of time. ${ }^{42}$

\section{Novel oral anticoagulant antagonists}

Idarucizumab is a monoclonal antibody fragment that binds dabigatran with high affinity and was approved by the FDA in 2015 following the completion of the Reversal Effects of Idarucizumab on Active Dabigatran (RE-VERSE AD) trial. ${ }^{43}$ In this trial, patients received $5 \mathrm{~g}$ of intravenous idarucizumab (Table 2). This dose was given as two $50-\mathrm{mL}$ bolus infusions, each containing $2.5 \mathrm{~g}$ of idarucizumab, administered no more than 15 minutes apart. The 5 -g dose was calculated to reverse the total body load of dabigatran that was associated with the $99^{\text {th }}$ percentile of the dabigatran levels.

Andexanet alfa (andexanet) is a specific reversal agent that is designed to neutralize the anticoagulant effects of both direct and indirect factor Xa inhibitors. ${ }^{44}$ The ongoing Prospective, Open-label Study of Andexanet Alfa in Patients Receiving a Factor Xa Inhibitor Who Have Acute Major Bleeding (ANNEXA-4) phase IIIb/IV study (NCT02329327) is aimed at evaluating the efficacy and safety of andexanet in patients with factor Xa inhibitorassociated acute major bleeding.

Several coagulation factor products have been investigated in small studies and are available for emergent periprocedural bleeding reversal in patients on NOACs. PCCs, recombinant factor VIIa (rFVIIa), and factor eight inhibitor bypassing activity (FEIBA) (Table 2) are already available for off-label use. PCCs have been shown to reverse the anticoagulation effects of factor $\mathrm{Xa}$ in healthy volunteers, ${ }^{45}$ animal models, ${ }^{46}$ and in vitro studies of healthy donor blood. ${ }^{47}$ rFVIIa has been shown to improve coagulation parameters in small studies using healthy volunteers on dabigatran. ${ }^{48}$ It similarly resulted in improvements in laboratory parameters in studies of factor Xa inhibitors using animal models and healthy

Table 2: Periprocedural Bleeding Reversal Agents

\begin{tabular}{|c|c|c|}
\hline Warfarin & Direct Thrombin Inhibitors & Factor Xa Inhibitors \\
\hline $\begin{array}{l}\text { Intravenous } 4 \mathrm{~F}-\mathrm{PPC}^{51} \\
\text { - INR: } 2-4,25 \text { units/kg } \\
\text { - INR: } 4-6,35 \text { units/kg } \\
\text { - INR: }>6,50 \text { units/kg }\end{array}$ & $\begin{array}{l}\text { Intravenous idarucizumab } 5 \mathrm{~g} \\
\text { - Give two } 50 \text {-mL bolus infusions, each containing } \\
2.5 \mathrm{~g} \text { of idarucizumab, no more than } 15 \text { minutes } \\
\text { apart }^{43}\end{array}$ & $\begin{array}{l}\text { Intravenous 4F-PPC } 51 \\
\text { - } 50 \text { units/kg }\end{array}$ \\
\hline $\begin{array}{l}\text { If } 4 F-P P C \text { is not available, use } \\
10-15 \mathrm{~mL} / \mathrm{kg} \text { of plasma }\end{array}$ & $\begin{array}{l}\text { If idarucizumab is not available, use } 50 \text { units } / \mathrm{kg} \text { of } \\
4 \mathrm{~F}-\mathrm{PPC}^{51}\end{array}$ & $\begin{array}{l}\text { Other coagulation products include } \\
\text { FEIBA, rFVIIa, aPCC }\end{array}$ \\
\hline
\end{tabular}

4F-PPC: four-factor prothrombin complex concentrate; INR: international normalized ratio; FEIBA: factor eight inhibitor bypassing activity; rFVIla: recombinant factor VIla; aPCC: activated prothrombin complex concentrate. 
donor blood. ${ }^{46,47}$ In an animal study, rFVIIa and PCC partially improved laboratory parameters; however, they did not reverse rivaroxaban-induced bleeding. ${ }^{46}$ In addition, there are studies that suggest that rFVIIa use significantly increased the risk of arterial thromboembolic events as compared with a placebo, an effect that was more pronounced in the elderly population. ${ }^{49}$ FEIBA contains the proenzymes of the prothrombin complex factors, prothrombin, FVII, FIX, and FX, but only very small amounts of their activation products, with the exception of FVIIa, which is contained in FEIBA in greater amounts. ${ }^{50}$ Small studies have shown improvement in coagulation parameters with FEIBA for factor Xa inhibitors as well as for dabigatran. ${ }^{48}$ The results were not consistent across all studies and coagulation parameters. Based on the limited data available, 4F-PCC is a reasonable option for emergency reversal of severe life-threatening bleeding in patients anticoagulated with oral factor Xa inhibitors. ${ }^{51}$

\section{Conclusions}

As outlined above, therapeutic anticoagulation is the mainstay of safely performing AF ablation procedures to minimize thromboembolic events. Stroke remains one of the most serious complications of AF ablation but, at the same time, there is a concern regarding intraprocedural and postprocedural bleeding stemming from the use of anticoagulants during this procedure. It should be remembered that anticoagulation is not the only factor responsible for bleeding or embolic phenomena in patients undergoing catheter ablation of AF. Transseptal puncture, high-caliber contact force, and/or induction of a "pop lesion" due to high tissue temperatures during radiofrequency energy delivery can account for cardiac perforation and tamponade irrespective of the anticoagulant used. On the other hand, char formation, endocardial damage, and thrombus formation due to insufficient heparin administration may contribute to an increased risk of stroke. ${ }^{52}$

New data from NOAC trials suggest that these agents can be used safely in an uninterrupted fashion, although they have an effect on the amount of heparin required to achieve a therapeutic ACT. The major concern of periprocedural uninterrupted use of NOACs has been the lack of reversal agents available. As mentioned before, idarucizumab is the only agent available that can reverse the effect of dabigatran, while agents for some other NOACs remain nonestablished. Cardiac tamponade during catheter ablation needs to be managed with pericardial drainage and hemodynamic support without waiting for a reversal agent. In addition, the administration of coagulation products (eg, PCCs, rFVIIa, FEIBA) appears to confer a protective action against periprocedural bleeding; notably, this is the recommended approach until more reversal agents become available. ${ }^{7,51,53}$ The development of NOAC reversal agents may help to minimize concerns regarding the use of NOACs for these procedures. Until more data are available, high-risk AF patients should be kept on long-term oral anticoagulation therapy after AF ablation.

\section{References}

1. Chugh SS, Havmoeller R, Narayanan K, et al. Worldwide epidemiology of atrial fibrillation: a Global Burden of Disease 2010 Study. Circulation. 2014;129(8):837-847.

2. Colilla S, Crow A, Petkun W, Singer DE, Simon T, Liu X. Estimates of current and future incidence and prevalence of atrial fibrillation in the U.S. adult population. Am J Cardiol. 2013;112(8):1142-1147.

3. Kim MH, Johnston SS, Chu BC, Dalal MR, Schulman KL. Estimation of total incremental health care costs in patients with atrial fibrillation in the United States. Circ Cardiovasc Qual Outcomes. 2011;4(3):313-320.

4. Go AS, Mozaffarian D, Roger VL, et al. Executive summary: heart disease and stroke statistics-2014 update: a report from the American Heart Association. Circulation. 2014;129(3):399-410.

5. Kannel WB, Wolf PA, Benjamin EJ, Levy D. Prevalence, incidence, prognosis, and predisposing conditions for atrial fibrillation: population-based estimates. Am J Cardiol. 1998;82(8A):2N-9N.

6. January CT, Wann LS, Albert JS, et al. 2014 AHA/ACC/HRS guideline for the management of patients with atrial fibrillation: executive summary: a report of the American College of Cardiology/American Heart Association Task Force on practice guidelines and the Heart Rhythm Society. Circulation. 2014;130(23):2071-2104.

7. Calkins H, Hindricks G, Cappato R, et al. 2017 HRS/EHRA/ ECAS/APHRS/SOLAECE expert consensus statement on catheter and surgical ablation of atrial fibrillation: executive summary. J Arrhythm. 2017;33(5):369-409.

8. Briceno DF, Madan N, Romero J, et al. Thromboembolic and bleeding risks in patients undergoing atrial fibrillation ablation: oral anticoagulation perspectives. Expert Opin Drug Saf. 2017;16(7):769-777.

9. Diener HC, Weber R, Lip GY, Hohnloser SH. Stroke prevention in atrial fibrillation: do we still need warfarin? Curr Opin Neurol. 2012;25(1):27-35.

10. Naccarelli GV, Cappato R, Hohnloser SH, et al. Rationale and design of VENTURE-AF: a randomized, open-label, active-controlled multicenter study to evaluate the safety of rivaroxaban and vitamin $\mathrm{K}$ antagonists in subjects undergoing catheter ablation for atrial fibrillation. J Interv Card Electrophysiol. 2014;41(2):107-116.

11. Knight BP. Anticoagulation for atrial fibrillation ablation: what is the optimal strategy? J Am Coll Cardiol. 2012;59(13):1175-1177.

12. Di Biase L, Burkhardt JD, Mohanty P, et al. Periprocedural stroke and management of major bleeding complications in patients undergoing catheter ablation of atrial fibrillation: the impact of periprocedural therapeutic international normalized ratio. Circulation. 2010;121(23):2550-2556.

13. Di Biase L, Burkhardt JD, Santangeli P, et al. Periprocedural stroke and bleeding complications in patients undergoing catheter ablation of atrial fibrillation with different anticoagulation management: results from the Role of Coumadin in Preventing Thromboembolism in Atrial Fibrillation (AF) Patients Undergoing Catheter Ablation (COMPARE) randomized trial. Circulation. 2014;129(25): 2638-2644.

14. Armbruster HL, Lindsley JP, Moranville MP, et al. Safety of novel oral anticoagulants compared with uninterrupted warfarin for catheter ablation of atrial fibrillation. Ann Pharmacother. 2015;49(3):278-284.

15. Sanford M, Plosker GL. Dabigatran etexilate. Drugs. 2008;68(12):1699-1709. 
16. Stangier J, Rathgen K, Stähle H, Gansser D, Roth W. The pharmacokinetics, pharmacodynamics and tolerability of dabigatran etexilate, a new oral direct thrombin inhibitor, in healthy male subjects. Br J Clin Pharmacol. 2007;64(3): 292-303.

17. Stangier J, Stahle H, Rathgen K, Fuhr R. Pharmacokinetics and pharmacodynamics of the direct oral thrombin inhibitor dabigatran in healthy elderly subjects. Clin Pharmacokinet. 2008;47(1):47-59.

18. Connolly SJ, Ezekowitz MD, Yusuf S, et al. Dabigatran versus warfarin in patients with atrial fibrillation. $N$ Engl J Med. 2009;361(12):1139-1151.

19. Kim JS, She F, Jongnarangsin K, et al. Dabigatran vs warfarin for radiofrequency catheter ablation of atrial fibrillation. Heart Rhythm. 2013;10(4):483-489.

20. Lakkireddy D, Reddy YM, Di Biase L, et al. Feasibility and safety of dabigatran versus warfarin for periprocedural anticoagulation in patients undergoing radiofrequency ablation for atrial fibrillation: results from a multicenter prospective registry. J Am Coll Cardiol. 2012;59(13): 1168-1174.

21. Calkins H, Gerstenfeld EP, Schilling R, Verma A, Willems S; RE-CIRCUIT Study Steering Committee. RE-CIRCUIT study-randomized evaluation of Dabigatran etexilate compared to warfarin in pulmonary vein ablation: assessment of an uninterrupted periprocedural anticoagulation strategy. Am J Cardiol. 2015;115(1):154-155.

22. Perzborn E, Strassburger J, Wilmen A, et al. In vitro and in vivo studies of the novel antithrombotic agent BAY 59-7939 - an oral, direct Factor Xa inhibitor. J Thromb Haemost. 2005;3(3):514-521.

23. Mueck W, Stampfuss J, Kubitza D, Becka M. Clinical pharmacokinetic and pharmacodynamic profile of rivaroxaban. Clin Pharmacokinet. 2014;53(1):1-16.

24. Weinz C, Schwarz T, Kubitza D, Mueck W, Lang D. Metabolism and excretion of rivaroxaban, an oral, direct Factor Xa inhibitor, in rats, dogs and humans. Drug Metab Dispos. 2009;37(5):1056-1064.

25. Patel MR, Mahaffey KW, Garg J, et al. Rivaroxaban versus warfarin in nonvalvular atrial fibrillation. $N$ Engl J Med. 2011;365(10):883-891.

26. Cappato R, Marchlinski FE, Hohnloser SH, et al. Uninterrupted rivaroxaban vs uninterrupted vitamin $\mathrm{K}$ antagonists for catheter ablation in non-valvular atrial fibrillation. Eur Heart J. 2015;36(28):1805-1811.

27. Raghavan N, Frost CE, Yu Z, et al. Apixaban metabolism and pharmacokinetics after oral administration to humans. Drug Metab Dispos. 2009;37(1):74-81.

28. Granger CB, Alexander JH, McMurray JJ, et al. Apixaban versus warfarin in patients with atrial fibrillation. $N$ Engl J Med. 2011;365(11):981-992.

29. Di Biase L, Lakkireddy D, Trivedu C, et al. Feasibility and safety of uninterrupted periprocedural apixaban administration in patients undergoing radiofrequency catheter ablation for atrial fibrillation: results from a multicenter study. Heart Rhythm. 2015;12(6):1162-1168.

30. Reynolds MR, Allison JS, Natale A, et al. A prospective randomized trial of apixaban dosing during atrial fibrillation ablation: the AEIOU trial. JACC Clin Electrophysiol. 2018;4(5):580-588.

31. Matsushima N, Lee F, Sato T, Weiss D, Mendell J. Bioavailability and safety of the factor Xa inhibitor edoxaban and the effects of quinidine in healthy subjects. Clin Pharm Drug Dev. 2013;2(4):358-366.

32. Ogata K, Mendell-Harary J, Tachibana M, et al. Clinical safety, tolerability, pharmacokinetics, and pharmacodynamics of the novel factor Xa inhibitor edoxaban in healthy volunteers. J Clin Pharmacol. 2010;50(7):743-753.

33. Giugliano RP, Ruff CT, Braunwald E, et al. Edoxaban versus warfarin in patients with atrial fibrillation. N Engl J Med. 2013;369(22):2093-2104.

34. Steffel J, Ruff CT, Hamershock RA, et al. First experience with edoxaban and atrial fibrillation ablation - Insights from the ENGAGE AF-TIMI 48 trial. Int J Cardiol. 2017;244:192-195.

35. Ruff CT, Giugliano RP, Braunwald E, et al. Comparison of the efficacy and safety of new oral anticoagulants with warfarin in patients with atrial fibrillation: a meta-analysis of randomised trials. Lancet. 2014;383(9921):955-962.

36. Maleki K, Mohammadi R, Hart D, Cotiga D, Farhat N, Steinberg JS. Intracardiac ultrasound detection of thrombus on transseptal sheath: incidence, treatment, and prevention. $J$ Cardiovasc Electrophysiol. 2005;16(6):561-565.

37. Wazni OM, Rossillo A, Marrouche NF, et al. Embolic events and char formation during pulmonary vein isolation in patients with atrial fibrillation: impact of different anticoagulation regimens and importance of intracardiac echo imaging. J Cardiovasc Electrophysiol. 2005;16(6):576-581.

38. Briceno DF, Villablanca PA, Lupercio F, et al. Clinical impact of heparin kinetics during catheter ablation of atrial fibrillation: meta-analysis and meta-regression. J Cardiovasc Electrophysiol. 2016;27(6):683-693.

39. Winkle RA, Mead RH, Engel G, Kong MH, Patrawala RA. The use of dabigatran immediately after atrial fibrillation ablation. J Cardiovasc Electrophysiol. 2012;23(3):264-268.

40. Thigpen JL, Limdi NA. Reversal of oral anticoagulation. Pharmacotherapy. 2013;33(11):1199-1213.

41. Bechtel BF, Nunez TC, Lyon JA, Cotton BA, Barrett TW. Treatments for reversing warfarin anticoagulation in patients with acute intracranial hemorrhage: a structured literature review. Int J Emerg Med. 2011;4(1):40.

42. Refaai MA, Kothari TH, Straub S, et al. Four-factor prothrombin complex concentrate reduces time to procedure in vitamin $\mathrm{K}$ antagonist-treated patients experiencing gastrointestinal bleeding: a post hoc analysis of two randomized controlled trials. Emerg Med Int. 2017;2017:8024356.

43. Pollack CV Jr, Reilly PA, Eikelboom J, et al. Idarucizumab for dabigatran reversal. N Engl J Med. 2015;373(6):511-520.

44. Siegal DM, Curnette JT, Connolly SJ, et al. Andexanet alfa for the reversal of Factor Xa inhibitor activity. N Engl J Med. 2015;373(25):2413-2242.

45. Eerenberg ES, Kamphuisen PW, Sijpkens MK, Meijers JC, Buller HR, Levi M. Reversal of rivaroxaban and dabigatran by prothrombin complex concentrate: a randomized, placebo-controlled, crossover study in healthy subjects. Circulation. 2011;124(14):1573-1579.

46. Godier A, Miclot A, Le Bonniec B, et al. Evaluation of prothrombin complex concentrate and recombinant activated factor VII to reverse rivaroxaban in a rabbit model. Anesthesiology. 2012;116(1):94-102.

47. Escolar G, Fernandez-Gallego V, Arellano-Rodrigo E, et al. Reversal of apixaban induced alterations in hemostasis by different coagulation factor concentrates: significance of studies in vitro with circulating human blood. PloS One. 2013;8(11):e78696.

48. Marlu R, Hodaj E, Paris A, Albaladejo P, Cracowski JL, Pernod G. Effect of non-specific reversal agents on anticoagulant activity of dabigatran and rivaroxaban: a randomised crossover ex vivo study in healthy volunteers. Thromb Haemost. 2012;108(2):217-224.

49. Levi M, Levy JH, Andersen HF, Truloff D. Safety of recombinant activated factor VII in randomized clinical trials. $N$ Engl J Med. 2010;363(19):1791-1800. 
50. Turecek PL, Váradi K, Gritsch H, Schwarz HP. FEIBA: mode of action. Haemophilia. 2004;10 Suppl 2:3-9.

51. Tomaselli GF, Mahaffey KW, Cuker A, et al. 2017 ACC Expert Consensus Decision Pathway on Management of Bleeding in Patients on Oral Anticoagulants: a report of the American College of Cardiology Task Force on Expert Consensus Decision Pathways. J Am Coll Cardiol. 2017;70(24):3042-3067.
52. Naccarelli GV, Gonzalez MD. Catheter ablation of atrial fibrillation: the need for studies to assess the efficacy and safety of novel anticoagulants. J Interv Card Electrophysiol. 2013;36(1):3-4.

53. Majeed A, Eelde A, Agren A, Schulman S, Holmström M. Thromboembolic safety and efficacy of prothrombin complex concentrates in the emergency reversal of warfarin coagulopathy. Thromb Res. 2012;129(2):146-151. 